\title{
Studies of Physico-chemical Properties and Cytotoxicity of Fruits of Syzygium jambos L. against HeLa and Vero Cell Lines
}

\author{
Fajilatun Nesa, Mohammad Shoeb, Md. Mazharul Islam and Md. Nazrul Islam \\ Department of Chemistry, University of Dhaka, Dhaka-1000, Bangladesh
}

(Received: May 2, 2021; Accepted: June 25, 2021; Published (Web): July 15, 2021)

\begin{abstract}
Syzygium jambos L. belonging to the family Myrtaceae has a long history of using as a dietary fruit and folklore medicine. Investigation of this fruit was carried out to evaluate the different chemical properties and biological activities. The moisture and ash content of the fruit sample were calculated as $86.88 \pm$ $0.61 \%$ and $0.29 \pm 0.02 \%$, respectively. Dried powder of the fruit was extracted successively with $n$ hexane, dichloromethane (DCM) and methanol (MeOH). UV-Visible and FT-IR spectral analyses confirmed the presence of unsaturated carboxylic acid in $n$-hexane, unsaturated ester in DCM and a diketone in $\mathrm{MeOH}$ extracts. Cytotoxicity assay of different extracts was carried out against HeLa and Vero cell lines and no extract was found to be cytotoxic. Total phenolic contents of the $n$-hexane, DCM and $\mathrm{MeOH}$ extracts were $15.39 \pm 0.24,31.32 \pm 0.25$ and $42.19 \pm 0.16 \mathrm{mg}$ gallic acid equivalent per gram of dry extract, respectively and total flavonoid content of $n$-hexane, DCM and MeOH extracts were $6.52 \pm 0.18,15.55 \pm 0.16$ and $8.36 \pm 0.16 \mathrm{mg}$ quercetin equivalent per gram of dry extract, respectively. This study establishes that $S$. jambos fruit can be a potential source of natural antioxidants.
\end{abstract}

Key words: Biological Activity, Chemical Activity, Cytotoxicity, Extraction, S. jambos

\section{Introduction}

Syzygium jambos L. (Alston), usually known as rose apple is a tropical fruit from the Myrtaceae family (Lim, 2012). It is widespread in Central America and Asia (Maskey et al., 1982). The $S$. jambos fruits possess a sweet flavor with a crisp and crunchy texture which is usually eaten raw. It is somewhat juicy and has a subtle rose-water aroma. The fruit can also be stewed, made into jams, jellies, confections (Norrington, 2001; Facciola, 1998). The fruit is effective as a diuretic and a tonic for healthier brain and liver (Djipa et al., 2000). It is also said to be effective in the treatment of deep ulcers and tumors (Leonard, 2008). According to the epidemiological studies, the risk of stroke and cancer can be lowered by frequent intake of the fruits (Beecher, 1999). Polyphenols are the most ample phytochemicals in our diets and fruits have the major contribution (Hertog, 1996). Polyphenols have shown potential health benefits among other bioactive compounds which is chiefly related to antioxidant capacity. Though the phytochemical analysis and biological activities of different parts of the plant are vastly reported, fewer reports have been found for the fruits. The objectives of the present study are to characterize the chemical constituents of fruits of $S$. jambos and determine the total phenolic and flavonoid contents along with the evaluation of its possible cytotoxicity profile.

\section{Materials and Methods}

Sample collection: The fruits of $S$. jambos were collected from different supermarkets in Dhaka city, Bangladesh during May 2019.

Chemicals and reagents: All solvents and analytical grade reagents used during the investigation were procured from E. Merck (Germany). Organic solvents in the extracts were completely removed by evaporation using freeze dryer (LABCONCO FreeZone).

Corresponding author: Mohammad Shoeb; Email: shoeb71@yahoo.com 
Determination of moisture and ash Content: Moisture and ash content of the fruits were determined according to standard AOAC 2000 (The Association of Official Analytical Chemists) method (Tasnim et al., 2020). Fresh fruits were first washed, air dried and weighed. Three crucibles were cleaned, dried well and initial weights were taken. Then $2.0 \mathrm{~g}$ sample was taken in each crucible. These were kept in oven at $105^{\circ} \mathrm{C}$ for about three hours. The samples were weighed again and moisture content was calculated as:

Moisture in the sample $(\%)=$

$\frac{\text { Weight before heating }- \text { Weight after heating }}{\text { Weight before heating }} \times 100$

For ash content, three crucibles with the samples were subjected to heat again at $700^{\circ} \mathrm{C}$ for about four hours. The samples were weighed again and ash content is calculated as:

Ash content $(\%)=$ $\frac{\text { Weight of the sample after heating }}{\text { Weight of the sample before heating }} \times 100$

Sample preparation and extraction: The sample was cut into small pieces and dried in room temperature and then in an oven at $40^{\circ} \mathrm{C}$. These were ground to fine powder and stored in air tight bag until extraction was carried out. Dried powder (210 g) was extracted with solvents of increasing order of polarity such as $n$-hexane, dichloromethane (DCM) and methanol $(\mathrm{MeOH})$. The extracts obtained after filtration using a cotton bed followed by Whatman number 1 filter paper were evaporated in a rotary evaporator at reduced temperature and pressure. The amount of $n$-hexane, DCM and $\mathrm{MeOH}$ extracts were calculated as 1.10, 0.2 and $38.0 \mathrm{~g}$, respectively.

Characterization techniques: UV-Visible and FT-IR spectroscopic analyses were carried out for the preliminary characterization of different functional groups present in the crude extracts. The UV-Visible spectra were taken using a Shimadzu UV-1800 spectrophotometer by dissolving the samples in $\mathrm{MeOH}$. The FT-IR spectra of each of the extracts were recorded as $\mathrm{KBr}$ pellets (Shimadzu FT-IR 4800S).

Cytotoxicity assay: The instruments used for cytotoxicity assay were Biological Safety Cabinet (Model: NU-400E, Nuaire, USA), $\mathrm{CO}_{2}$ Incubator (Nuaire, USA), Trinocular microscope with camera (Optika, Italy) and Hemocytometer. The used consumables were 48-well plate. In brief, HeLa, a human cervical carcinoma cell line was maintained in DMEM (Dulbecco's Modified Eagles' medium) containing $1 \%$ penicillin-streptomycin (1:1) and $0.2 \%$ gentamycin and $1 \%$ Fetal Bovine Serum (FBS). HeLa Cells $\left(4 \times 10^{4} / 200 \mu \mathrm{l}\right)$ and Vero cells $\left(3 \times 10^{4} / 200\right.$ $\mu \mathrm{l})$ were seeded onto 48 - well plate and incubated at $37^{\circ} \mathrm{C}+5 \% \mathrm{CO}_{2}$. Next day, $50 \mu \mathrm{l}$ sample (filtered) was added to each well. Cytotoxicity was examined under an inverted light microscope after 48hours of incubation. Duplicate wells were used for each sample (Saroar et al., 2020; Jae et al., 2018).

Total phenolic content (TPC): The total phenolic content of each of the extracts was determined using the Folin-Ciocalteu reagent, following the method described by Wolfe (Wolfe et al., 2003) with slight modifications. For this, $0.5 \mathrm{ml}$ of different extracts was taken separately in different test-tubes and $5 \mathrm{~mL}$ of Folin-Ciocalteu's reagent and $4 \mathrm{~mL}$ sodium carbonate were added. The solutions were then vortexed for 20 seconds for proper mixing and allowed to stand for $30 \mathrm{~min}$ at room temperature for development of color. After 30 minutes of reaction, the absorbance was measured against the reagent blank with a double beam UV-Visible spectrophotometer at $765 \mathrm{~nm}$. Three readings were taken per each experimental sample to get reproducible results.

Total flavonoid content (TFC): Total flavonoid content of the sample was determined by the aluminum chloride colorimetric assay (Chang et al. 2002). Quercetin was used to make the standard calibration curve. Standard solutions were prepared by serial dilution using $\mathrm{MeOH}(2-100 \mu \mathrm{g} / \mathrm{ml})$. An amount of $0.6 \mathrm{ml}$ of diluted standard quercetin solutions or extracts was separately added with 2.5 $\mathrm{ml}$ solution of aluminum chloride and $\mathrm{NaOAc}$. The 
mixed solution was incubated for $60 \mathrm{~min}$ at room temperature. The absorbance of the reaction mixtures was measured against reagent blank at 430nm with a double beam UV-Visible spectrophotometer.

\section{Results and Discussion}

The amount of moisture content is an important indication of food value in food chemistry. Change in moisture content will dramatically affect the flavor and texture as well as the chemical and physical properties and ash content of the fruits, which are simply determined by burning away the organic contents, leaving the residual inorganic minerals. The average percentage of moisture and ash content in the S. jambos fruits were $86.88 \pm 0.61$ and $0.29 \pm 0.02$, respectively. The FT-IR spectral data of $n$-hexane, DCM and $\mathrm{MeOH}$ extracts with assignment of peaks have been presented in Table 1.

Table 1. FT-IR absorption frequency and peak assignment.

\begin{tabular}{|c|c|c|c|c|c|}
\hline \multicolumn{2}{|c|}{$n$-Hexane extract } & \multicolumn{2}{|c|}{ DCM extract } & \multicolumn{2}{|c|}{$\mathrm{MeOH}$ extract } \\
\hline $\begin{array}{l}\text { Frequency }\left(\mathrm{cm}^{-1}\right) \\
\text { (Vibrational mode) }\end{array}$ & Peaks & $\begin{array}{l}\text { Frequency }\left(\mathrm{cm}^{-1}\right) \\
\text { (Vibrational mode) }\end{array}$ & Peaks & $\begin{array}{l}\text { Frequency }\left(\mathrm{cm}^{-1}\right) \\
\text { (Vibrational mode) }\end{array}$ & Peaks \\
\hline $3402(\mathrm{~s})$ & $\mathrm{O}-\mathrm{H}$ & $3405(\mathrm{~s})$ & $\begin{array}{c}\mathrm{O}-\mathrm{H} \\
\text { (Alcoholic) }\end{array}$ & $3399(\mathrm{~s})$ & O-H (Alcoholic) \\
\hline $2924(\mathrm{~s})$ & $\mathrm{C}-\mathrm{H}\left(\mathrm{sp}^{3}\right)$ & 2927 (s) & $\mathrm{C}-\mathrm{H}\left(\mathrm{sp}^{3}\right)$ & 2934 (s) & $\mathrm{C}-\mathrm{H}\left(\mathrm{sp}^{3}\right)$ \\
\hline $1691(\mathrm{~s})$ & $\begin{array}{c}\mathrm{C}=\mathrm{O} \\
\text { (Carboxylic) }\end{array}$ & $1721(\mathrm{~s})$ & $\begin{array}{l}\mathrm{C}=\mathrm{O} \\
\text { (Ester) }\end{array}$ & $1730(\mathrm{~s})$ & $\mathrm{C}=\mathrm{O}$ (Ketonic) \\
\hline $1658(\mathrm{~s})$ & $\mathrm{C}=\mathrm{C}$ & $1656(\mathrm{~s})$ & $\mathrm{C}=\mathrm{C}$ & 1643 (s) & $\mathrm{C}=\mathrm{O}$ (Enolic) \\
\hline $1460(b)$ & $\mathrm{CH}_{2}$ & 1458 (b) & $\mathrm{CH}_{2}$ & 1418 (b) & $\mathrm{CH}_{2}$ \\
\hline $1380(b)$ & $\mathrm{CH}_{3}$ & 1380 (b) & $\mathrm{CH}_{3}$ & 1059 (b) & $\mathrm{C}-\mathrm{O}$ \\
\hline & & & & 818 (ор) & $=\mathrm{C}-\mathrm{H}$ \\
\hline & & & & 777 (ор) & $=\mathrm{C}-\mathrm{H}$ (Aromatic) \\
\hline
\end{tabular}

Note: s-stretching, b-bending, op-out of plane

From the FT-IR spectrum, it was evident that the $n$-hexane, DCM and $\mathrm{MeOH}$ extracts may contain compounds with carboxylic acid ( $\mathrm{RCOOH})$, ester (RCOOR) and diketone ( $\left.\mathrm{RCOCH}_{2} \mathrm{COR}\right)$ groups, respectively (Lampman et al.. 1994). The UV-Visible spectral data of $n$-hexane and DCM extracts at 500 and $250 \mu \mathrm{g} / \mathrm{ml}$ are summarized in Table 2. UVVisible spectroscopic data of the $n$-hexane extract showed absorbance at $292 \mathrm{~nm}$ is quite intense and can be assumed that the peak is for $n \rightarrow \Pi^{*}$ transition of $\mathrm{C}=\mathrm{O}$ group. Another intense peak at $264 \mathrm{~nm}$ is for $\Pi \rightarrow \Pi^{*}$ transition of conjugated $\Pi$ electron system. The absorbance ranging from $603-662 \mathrm{~nm}$ is for ketone containing both $\Pi$-system and lone pair of electrons (enones). The peak at $286 \mathrm{~nm}$ is for enones and $279 \mathrm{~nm}$ is for simple ketone.

The UV-Visible spectral absorption of DCM extract at $227 \mathrm{~nm}$ is quite intense and can be assumed for unsaturated carboxylic acid or ester. The peak at $277 \mathrm{~nm}$ is for conjugated $\mathrm{C}=\mathrm{O}$. The absorbance at $659 \mathrm{~nm}$ (visible region) is for ketone containing both ח-system and lone pair of electrons (enones). On the other hand, the peaks at $399 \mathrm{~nm}$ and $211 \mathrm{~nm}$ can be assumed for $\alpha, \beta$ unsaturated ketone.

The cytotoxicity assay of the $n$-hexane, DCM and $\mathrm{MeOH}$ extracts of fruits of $S$. jambos were tested against both HeLa and Vero cell lines. The samples were dissolved in 2.5\% DMSO in aqueous solvent. However, no cytotoxicity was observed for all the tested fractions on both HeLa and Vero cell line (Table 3). The cytotoxic effects along with the solvent (2.5\% DMSO) are shown in Figure 1.

Previous report also suggests that $S$. jambos leaf extract exhibits strong cytotoxic activity against Human Leukemia cell line or HL-60 (Yang et al., 2000). The TPC was estimated from a standard 
calibration curve of gallic acid $(20-400 \mu \mathrm{g} / \mathrm{ml})$ and TPC contents of the fruits was expressed as $\mathrm{mg}$ of gallic acid equivalents per gram of dry extract using the equation, $\mathrm{y}=0.0062 \mathrm{x}+0.0766 ; \mathrm{r}^{2}=0.9985$

(Figure 2a).

Table 2. UV-Visible spectral data of $n$-hexane and DCM extract at 500 and $250 \mu \mathrm{g} / \mathrm{ml}$.

\begin{tabular}{|c|c|c|c|c|c|c|c|}
\hline \multicolumn{4}{|c|}{$n$-hexane extract } & \multicolumn{4}{|c|}{ DCM extract } \\
\hline \multicolumn{2}{|c|}{$500 \mu \mathrm{g} / \mathrm{ml}$} & \multicolumn{2}{|c|}{$250 \mu \mathrm{g} / \mathrm{ml}$} & \multirow{2}{*}{$\begin{array}{c}500 \mu \mathrm{g} / \mathrm{ml} \\
\lambda\end{array}$} & \multicolumn{3}{|c|}{$250 \mu \mathrm{g} / \mathrm{ml}$} \\
\hline$\lambda$ & A & $\lambda$ & A & & A & $\lambda$ & A \\
\hline 662 & 0.095 & 661 & 0.082 & 659 & 0.059 & 659 & 0.048 \\
\hline 603 & 0.072 & 601 & 0.073 & 277 & 2.179 & 399 & 0.078 \\
\hline 292 & 4.000 & 286 & 4.000 & 227 & 4.000 & 275 & 1.075 \\
\hline 264 & 4.000 & 279 & 4.000 & & & 211 & 4.000 \\
\hline 247 & 4.000 & 234 & 4.000 & & & & \\
\hline 241 & 4.000 & & & & & & \\
\hline
\end{tabular}

$\lambda=$ Wavelenght in nanometer, $\mathrm{A}=$ Absorbance.

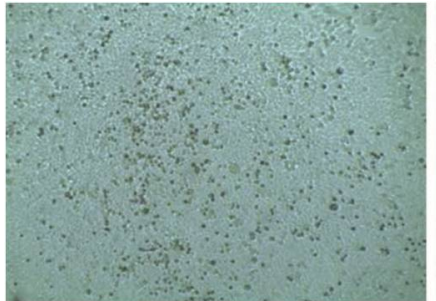

(a) Solvent (+)

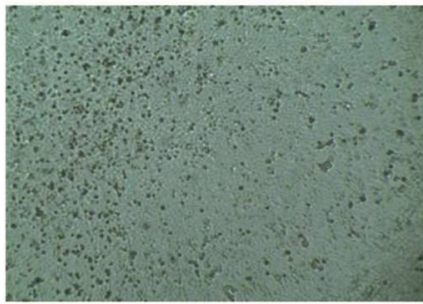

(e) $\mathrm{MeOH}$

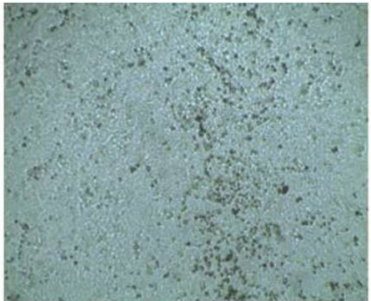

(b) Solvent (-)

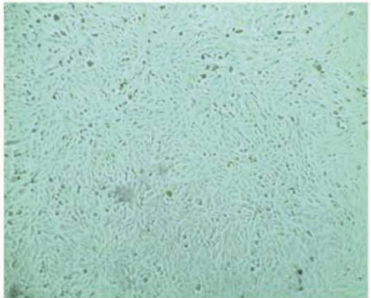

(f) Solvent (+)

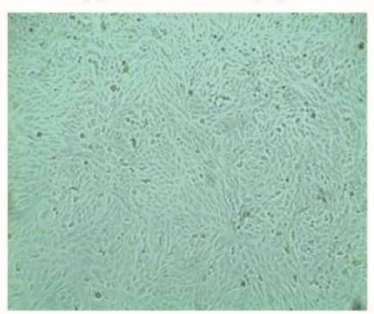

(i) DCM

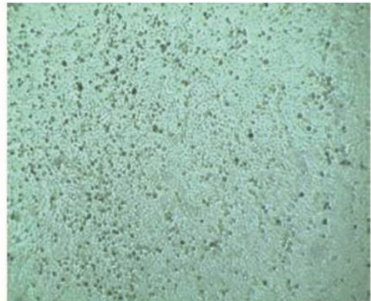

(c) n-hexane

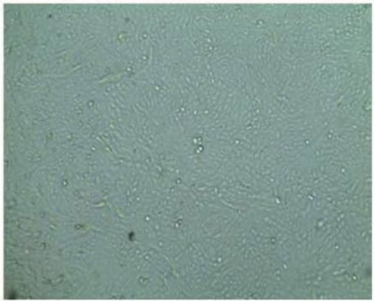

(g) Solvent (-)

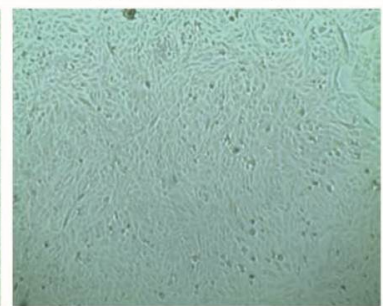

(j) $\mathrm{MeOH}$

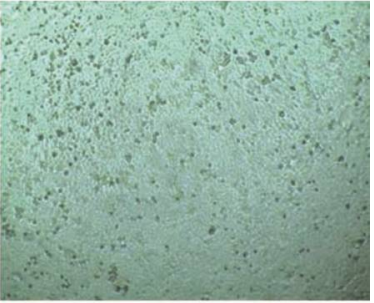

(d) DCM

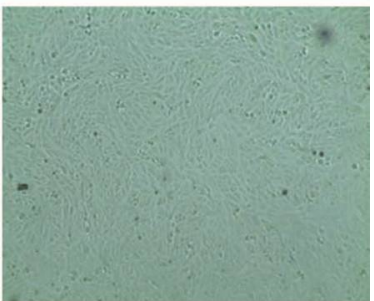

(h) n-hexane

Figure 1. Cytotoxicity assay of different fractions using 2.5\% DMSO as solventon HeLa cell line (a-e) and Vero cell line (f-j). 

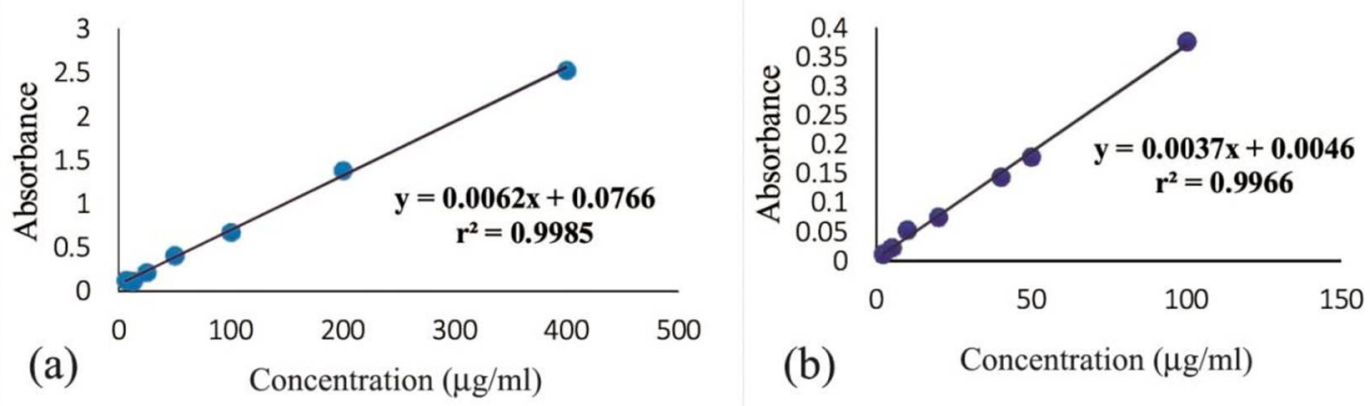

Figure 2. Standard calibration curve for (a) Gallic acid and (b) Quercetin.

Table 3. Cytotoxicity test of different extracts.

\begin{tabular}{lll}
\hline \multirow{2}{*}{ Sample ID } & \multicolumn{2}{c}{ Survival of the cell } \\
\cline { 2 - 3 } & HeLa & Vero \\
\hline$n$-hexane & $>95 \%$ & $>95 \%$ \\
DCM & $>95 \%$ & $>95 \%$ \\
Methanol & $>95 \%$ & $>95 \%$ \\
Solvent (+) & $>95 \%$ & $>95 \%$ \\
Solvent (-) & $100 \%$ & $100 \%$ \\
\hline
\end{tabular}

The total phenolic content of $n$-hexane, DCM and $\mathrm{MeOH}$ extracts were found to be $15.39 \pm 0.24$, $31.32 \pm 0.25$ and $42.19 \pm 0.16 \mathrm{mg} / \mathrm{g}$, respectively. Among the three, the $\mathrm{MeOH}$ extract contains maximum amount of total phenolic $(42.19 \pm 0.16 \mathrm{mg}$ gallic acid equivalent per gram of dry extract) content. The phenolic compounds have redox properties which are responsible for antioxidant activity. As the $\mathrm{MeOH}$ extract showed the highest phenolic content among others, it implies that the extract has more promising antioxidant activity than the other two extracts. TFC was estimated from a standard curve of quercetin $(2.5-100 \mu \mathrm{g} / \mathrm{ml})$, and expressed as $\mathrm{mg}$ quercetin equivalents per gram of dry extract using the equation, $y=0.0037 x+0.0046$; $r^{2}=0.9966$, obtained from Figure 2b. The TFC of $n$ hexane, DCM and $\mathrm{MeOH}$ extracts were $6.52 \pm 0.18$, $15.55 \pm 0.16$ and $8.36 \pm 0.16 \mathrm{mg} / \mathrm{g}$, respectively. It was observed that the DCM extract contains maximum amount of flavonoids $(15.55 \pm 0.16 \mathrm{mg}$ quercetin equivalent per gram of dry extract). The $n$ hexane extract contains lowest amount of flavonoid content $(6.52 \pm 0.18 \mathrm{mg}$ quercetin equivalent per gram of dry extract accordingly). Flavonoids have been known to exhibit antioxidant activity. The effectiveness of antioxidant activity of flavonoids depends on the number and position of the free $\mathrm{OH}$ groups. The highest flavonoids content indicates a higher antioxidant activity with a greater number of free $\mathrm{OH}$ groups. The results of phenolic and flavonoid content present in $S$. jambos fruits are in agreement to that reported previously. (Abeysuriya et al., 2020).

\section{Conclusions}

Determination of the moisture content is important for assessing the food value and preservation of the fruits. This fruit contains a little amount of ash, determination of which is important because the amount of minerals can determine the physiochemical properties of the fruits contributing nutrition, quality, microbial viability etc. The $\mathrm{MeOH}$ and DCM extracts of the fruits of $S$. jambos have shown higher phenolic and flavonoid contents as compared to $n$-hexane extract. So, the $\mathrm{MeOH}$ and DCM extracts contain compounds having significant antioxidant, anti-inflammatory and antimutagenic activities. However, no extract showed cytotoxicity which may eliminate their possibility of using as a cytotoxic agent.

\section{Acknowledgements}

The authors are grateful to International Science Programme (ISP), Uppsala University, Sweden for financial supports. 


\section{References}

Abeysuriya, H.I., Bulugahapitiya, V.P. and Pulukkuttige, J.L. 2020. Total vitamin C, ascorbic acid, dehydroascorbic acid, antioxidant properties, and iron content of underutilized and commonly consumed fruits in Sri Lanka. Int. J. Food Sci. 13, Article ID 4783029.https://doi.org/10.1155/2020/4783029.

Beecher, G.R. 1999. Phytonutrients' role in metabolism: effects on resistance to degenerative processes. Nutr Rev. 57(9 Pt 2), 3-6. doi: 10.1111/j.17534887.1999.tb01800.x. PMID: 10568344.

Chang, C., Yang, M., Wen, H., Chern, J. 2002. Estimation of total flavonoid content in propolis by two complementary colorimetric methods.J. Food Drug Anal. 10, 178-182.

Djipa, C.D., Delmée, M. and Quetin-Leclercq, J. 2000. Antimicrobial activity of bark extracts of Syzygium jambos (L.) alston (Myrtaceae). J. Ethnopharmacol. 71(1-2), 307-313. doi: 10.1016/s0378-8741(99)001865. PMID: 10904178.

Facciola, S. 1998. Cornucopia II. Kampong Publications, California. ISBN: 0-9628087-25.

Hertog, M. 1996. Epidemiological evidence on potential health properties of flavonoids. Proc. Nutri. Soc. 55 (1B), 385-397. doi:10.1079/PNS19960037.

Jae, S. Y., Dahae, L., Seoung, R. L., Jae, W. L., Chang-IK, C., Tae Su, J., Ki Sung, K. and Ki Hyun, K. 2018. Chemical characterization of cytotoxic indole acetic derivative from mulberry fruit (Muras alba L.) against human cervical cancer. Bioorg. Chem. 76, 28-36.
Lampman, G.M., Pavia, D.L., Kriz, G.S. and Vyvyan, J.R. Spectroscopy, Fourth edition 1994.

Leonard, D.B. 2008. Syzygium jambos ('Öhi'aLoke). In: Medicine at your Feet: Healing Plants of the Hawaiian Kingdom. IM Publishing.

Lim, T.K. 2012. Myrtaceae, Syzygium jambos. In: Edible Medicinal and Non-medicinal Plants: Fruits, Vol.3, Springer, p. 765.

Maskey, K. and Shah, B.B. 1982. Sugars in some Nepalese edible wild fruits. J. Nepal Chem. Soc.2, 23-30. http://indianmedicine.eldoc.ub.rug.nl/id/eprint/23738.

Norrington, L. 2001. Tropical Food Gardens. Bloomings Books (Melbourne). ISBN: $1876473-41 \mathrm{x}$.

Saroar, F., Shoeb, M., Islam, M.N., Rhaman, M.M., Islam, R. and Parvin, N. 2020. Studies of marine seaweeds Sargassum flavicans. Asian J. Pharmacogn. 4, 52-58.

Tasnim, T.K., Akter, S., Shoeb, M. and Farha, W. 2020. Fatty acids composition and heavy metals in marine fish samples from the south-eastern part of Bangladesh. Org. Chem. Plus. 1, 46-51.

Wolfe, K., Wu, X. and Liu, R. H. 2003. Antioxidant activity of apple peels. J. Agr. Food Chem. 51, 609614.

Yang, L.L., Lee, C.Y. and Yen, K.Y. 2000. Induction of apoptosis by hydrolysable tannins from Eugenia jambos L. on human leukemia cells. Cancer Letters, 157, 65-75. 